\title{
Editorial \\ Welcome to Physchem: Status and Prospects
}

\author{
Jacinto Sá ${ }^{1, *(1)}$, Sergei Manzhos ${ }^{2}\left(\mathbb{C}\right.$ and Vincenzo Barone ${ }^{3}(\mathbb{C})$ \\ 1 Department of Chemistry-Ångström Laboratory, Uppsala University, 75120 Uppsala, Sweden \\ 2 School of Materials and Chemical Technology, Tokyo Institute of Technology, Ookayama 2-12-1, \\ Meguro-ku, Tokyo 152-8552, Japan; manzhos.s.aa@m.titech.ac.jp \\ 3 Scuola Normale Superiore di Pisa, Piazza dei Cavalieri, 56126 Pisa, Italy; vincenzo.barone@sns.it \\ * Correspondence: jacinto.sa@kemi.uu.se; Tel.: +46-18-471-6806
}

check for updates

Citation: Sá, J.; Manzhos, S.; Barone, V. Welcome to Physchem: Status and Prospects. Physchem 2022, 2, 16-17. https://doi.org/10.3390/ physchem 2010002

Received: 23 January 2022

Accepted: 22 February 2022

Published: 27 February 2022

Publisher's Note: MDPI stays neutral with regard to jurisdictional claims in published maps and institutional affiliations.

Copyright: () 2022 by the authors Licensee MDPI, Basel, Switzerland. This article is an open access article distributed under the terms and conditions of the Creative Commons Attribution (CC BY) license (https:// creativecommons.org/licenses/by/ $4.0 /)$.
We begin with passing on our very best wishes to the community for a healthy and prosperous 2022. We have prepared this short Editorial for the new year, to update our readers and authors with some key metrics from our first full year in operation.

The launch of PhysChem has created a journal dedicated specifically to the field of physical chemistry within the MDPI portfolio of natural-science-oriented journals. The field of physical chemistry has been gaining in importance; indeed, being an intrinsically multidisciplinary area focused, in particular, on studies of how matter behaves on a molecular and atomic level, it is a field of primary importance for the development of many novel technologies, from fuel cells to batteries to catalytic systems. A number of MDPI journals focused on their applications (including Nanomaterials, Materials, and Molecules) have achieved significant impact (also reflected in their Impact Factor). With a scope including the nexus of underlying physics, chemistry, and computational mathematics as well as data-driven approaches including machine learning and artificial intelligence applied to problems of physical chemistry, PhysChem is well positioned to attract innovative papers and enjoy a sustained rise in impact in the near future.

PhysChem did well in its inception year, despite the COVID-19 pandemic and the other challenges faced when starting a new journal. We are proud and grateful to the authors, reviewers, Editorial Board, advisors, and many others who significantly contributed to this journal's successful launch. We extend a warm welcome to Cheeria Liang, our new Managing Editor, to whom I am very thankful. Several additional new Board Members have been enrolled as part of our Editorial Board. We warmly welcome Dr. Charlotte Vogt of Israel Institute of Technology and Prof. Gianfranco Risuleo of Sapienza University of Rome, and anticipate their support in shaping the future of PhysChem in the coming years.

In 2021, we published 21 articles, and we were listed in the DOAJ and J-Gate databases. The key sections of PhysChem are Catalysis, Electrochemistry, Physical Organic Chemistry, Nanoscience, Kinetics and Thermodynamics, and Surface Science. Figure 1 shows the frequency of keywords in the published papers and their interconnection. At PhysChem, we are deeply grateful for all contributions. With more exciting challenges and changes in the coming months, we begin the new year welcoming your excellent and exciting contributions in the key areas of Physical Chemistry and Chemical Physics.

The year 2022 started with the advertisement of several new Special Issues, for which we welcome your contributions. This is also the year we will launch the PhysChem $\mathrm{PhD}$ award for the best thesis published in the last 12 months, for which we welcome nominations and applications.

We would like to finish this Editorial by wishing you all the health in the world. We are hopeful for the end of the pandemic as we currently know it, and that we will return to some normality with in-person events and warm interactions, which we all miss and have become to value even more. 


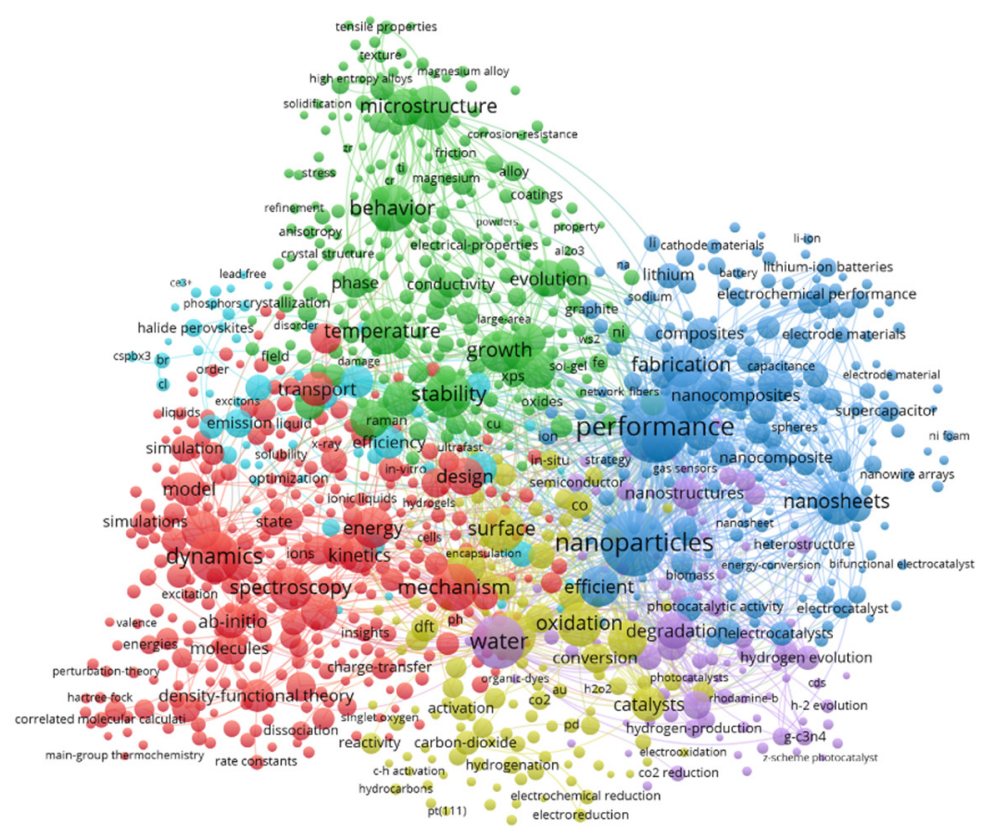

Figure 1. Incidence rate of keywords in PhysChem articles in the categories of Physical Chemistry and Chemical Physics published in 2018-2021.

Author Contributions: The authors contributed equally to the drafting of the manuscript. All authors have read and agreed to the published version of the manuscript.

Funding: This research received no external funding.

Institutional Review Board Statement: Not applicable.

Informed Consent Statement: Not applicable.

Data Availability Statement: Not applicable.

Conflicts of Interest: There are not conflict of interest. 